\title{
Prevalence of RFC1-mediated spinocerebellar ataxia in a North American ataxia cohort
}

Dona Aboud Syriani, Darice Wong, PhD, Sameer Andani, BS, Claudio M. De Gusmao, MD, Yuanming Mao, BS, May Sanyoura, PhD, Giacomo Glotzer, Paul J. Lockhart, PhD, Sharon Hassin-Baer, MD,

Vikram Khurana, MD, PhD, Christopher M. Gomez, MD, PhD, Susan Perlman, MD, Soma Das, PhD, and

Brent L. Fogel, MD, PhD

Neurol Genet 2020;6:e440. doi:10.1212/NXG.0000000000000440

\begin{abstract}
Objective

We evaluated the prevalence of pathogenic repeat expansions in replication factor $\mathrm{C}$ subunit 1 $(R F C 1)$ and disabled adaptor protein $1(D A B 1)$ in an undiagnosed ataxia cohort from North America.
\end{abstract}

\section{Methods}

A cohort of 596 predominantly adult-onset patients with undiagnosed familial or sporadic cerebellar ataxia was evaluated at a tertiary referral ataxia center and excluded for common genetic causes of cerebellar ataxia. Patients were then screened for the presence of pathogenic repeat expansions in RFC1 (AAGGG) and DAB1 (ATTTC) using fluorescent repeat-primed PCR (RPPCR). Two additional undiagnosed ataxia cohorts from different centers, totaling 302 and 13 patients, respectively, were subsequently screened for RFC1, resulting in a combined 911 subjects tested.

\section{Results}

In the initial cohort, 41 samples were identified with 1 expanded allele in the $R F C 1$ gene (6.9\%), and 9 had 2 expanded alleles (1.5\%). For the additional cohorts, we found 20 heterozygous samples (6.6\%) and 17 biallelic samples (5.6\%) in the larger cohort and 1 heterozygous sample $(7.7 \%)$ and 3 biallelic samples $(23 \%)$ in the second. In total, 29 patients were identified with biallelic repeat expansions in RFC1 (3.2\%). Of these 29 patients, 8 (28\%) had a clinical diagnosis of cerebellar ataxia, neuropathy, and vestibular areflexia syndrome (CANVAS), 14 had cerebellar ataxia with neuropathy (48\%), 4 had pure cerebellar ataxia (14\%), and 3 had spinocerebellar ataxia (10\%). No patients were identified with expansions in the DAB1 gene (spinocerebellar ataxia type 37 ).

\section{Conclusions}

In a large undiagnosed ataxia cohort from North America, biallelic pathogenic repeat expansion in $R F C 1$ was observed in $3.2 \%$. Testing should be strongly considered in patients with ataxia, especially those with CANVAS or neuropathy.

\author{
Correspondence \\ Dr. Fogel \\ bfogel@ucla.edu \\ or Dr. Das \\ sdas@bsd.uchicago.edu
}

\section{RELATED ARTICLE}

\section{Editorial}

Intronic pentanucleotide expansion in the replication factor 1 gene $(R F C 1)$ is a major cause of adult-onset ataxia

Page e436

From the Department of Neurology (D.A.S., D.W., Y.M., S.P., B.L.F.), Program in Neurogenetics, David Geffen School of Medicine, University of California, Los Angeles; Department of Neurology (D.W., B.L.F.), Clinical Neurogenomics Research Center, David Geffen School of Medicine, University of California, Los Angeles; Department of Human Genetics (S.A., M.S., S.D.), University of Chicago, IL; Department of Neurology (C.M.D.G., V.K.), Brigham and Women's Hospital and Harvard Medical School, Boston, MA; Department of Neurology (G.G., C.M.G.), University of Chicago, IL; Bruce Lefroy Centre (P.J.L.), Murdoch Children's Research Institute; Department of Paediatrics (P.J.L.), University of Melbourne, Parkville, Australia; Sackler Faculty of Medicine (S.H.-B.), Tel-Aviv University, Tel-Aviv, Israel; and Department of Human Genetics (B.L.F.), David Geffen School of Medicine, University of California, Los Angeles.

Go to Neurology.org/NG for full disclosures. Funding information is provided at the end of the article.

The Article Processing charge was funded by the authors.

This is an open access article distributed under the terms of the Creative Commons Attribution-NonCommercial-NoDerivatives License 4.0 (CC BY-NC-ND), which permits downloading and sharing the work provided it is properly cited. The work cannot be changed in any way or used commercially without permission from the journal. 


\section{Glossary}

CANVAS = cerebellar ataxia, neuropathy, and vestibular areflexia syndrome; DAB1 = Disabled Adaptor Protein $1 ; \boldsymbol{R F C 1}=$ replication factor C subunit 1; SCA37 = spinocerebellar ataxia type 37.

Cerebellar ataxia is a heterogeneous genetic disorder characterized by inability to control balance and coordination. Roughly $50 \%$ of patients remain undiagnosed despite advanced genomic testing. ${ }^{1-4}$ The most common genetic ataxias, as well as several rarer forms, are caused by nucleotide repeat expansions, which typically require targeted non-sequencebased testing to identify. ${ }^{5-8}$

Recent studies identified a recessive intronic (AAGGG) repeat expansion in replication factor $\mathrm{C}$ subunit $1(R F C 1)$ related to cerebellar ataxia, neuropathy, and vestibular areflexia syndrome (CANVAS) in Australia and the United Kingdom. ${ }^{9,10}$ In addition, this expansion may be responsible for up to $22 \%(33 / 150)$ of sporadic cerebellar ataxia and $63 \%$ $(32 / 51)$ of ataxia associated with sensory neuropathy. ${ }^{9}$ Similarly, a dominant pathologic pentanucleotide (ATTTC) repeat insertion was identified within a normal (ATTTT) tandem repeat element in the intronic $5^{\prime}$ untranslated region of the disabled adaptor protein $1(D A B 1)$ gene causing spinocerebellar ataxia type 37 (SCA37) in patients from the southern Iberian Peninsula. ${ }^{11}$

To address the frequency of these repeat expansion disorders in North America, we assessed a large cohort of 596 patients from the United States with unidentified cerebellar ataxia. We identified biallelic $R F C 1$ expansion in $1.5 \%(\mathrm{n}=9)$ and found no patients with a pathogenic $D A B 1$ expansion. We further tested 2 additional cohorts from different centers (the larger of which consisted of approximately one-third samples from patients in Canada, with the remainder from the United States) and identified RFC1-mediated ataxia cases in 5.6\% (17/302) and $23 \%(3 / 13)$, respectively, for a total prevalence of $3.2 \%$ (29/911).

\section{Methods}

\section{Standard protocol approvals, registrations, and patient consents}

Patients were enrolled at the University of California, Los Angeles (UCLA) Ataxia Center, clinically assessed for acquired causes of ataxia, and then considered for genetic causes. ${ }^{2}$ Only patients with negative testing for the common genetic ataxias (SCA1, SCA2, SCA3, SCA6, SCA7, and Friedreich ataxia) were included in this study. The majority ( $\sim$ two-thirds) were adult and sporadic onset. All patients consented for DNA collection for genetic analysis. Peripheral blood was collected from patients, and DNA was then isolated and purified using the Gentra Puregene Blood Kit (Qiagen) for genetic testing. The study methods used were approved by the UCLA Institutional Review Board. Additional DNA samples from 302 patients enrolled at the University of Chicago and 13 patients enrolled at the Brigham and Women's Hospital under institutional review board-approved procedures with identical inclusion criteria were subsequently tested as well. For the purpose of assessing disease prevalence, only probands from affected families were included in this study, and all pathogenic repeat expansions were confirmed in additional affected family members when available.

\section{Repeat expansion testing}

\section{RFC1 gene repeat expansion analysis}

Fluorescent repeat-primed PCR (RP-PCR) was performed to detect $R F C 1$ pathogenic (AAGGG) $)_{\mathrm{n}}$ alleles using previously published primers ${ }^{9,10}$ with an optimized touchdown PCR protocol and Qiagen HotStarTaq. One primer set included the forward 5'FAM-ACTGACAGTGTTTTTGCCTGT-3' primer, the anchor 5'-CAGGAAACAGCTATGACC-3' primer, and the repeat 5'-CAGGAAACAGCTATGACCAAGGGAAGGGA AGGGAAGGGAAGGG-3' primer that identifies the (AAGGG) repeats. A second primer set included the forward 5'FAMTCAAGTGATACTCCAGCTACACCGT- $3^{\prime}$ primer, the anchor 5'-CAGGAAACAGCTATGACC-3' primer, and 3 repeat primers that identify the (AAGGG) repeats 5'-CAGGAAACAGCTATGACCAACAGAGCAAGACTCTGTTTCA AAAAAGGGAAGGGAAGGGAAGGGAA-3'，5'-CAGGAAACAGCTATGACCAACAGAGCAAGACTCTGTTTCA AAAAGGGAAGGGAAGGGAAGGGAA-3', and 5'-CAGGAAACAGCTATGACCAACAGAGCAAGACTCTGTT TCAAAAGGGAAGGGAAGGGAAGGGAA-3'. Fragment length analysis was performed using an Applied Biosystems 3730xl DNA Analyzer with Peak Scanner software (v. 2.0). To determine whether the genotype of samples with positive RPPCR results was heterozygous or biallelic, standard PCR was performed using published primers, ${ }^{9}$ forward $5^{\prime}$-TCAAGTGATACTCCAGCTACACCGTTGC-3' primer and the reverse $5^{\prime}$ GTGGGAGACAGGCCAATCACTTCAG-3' primer. Observation of a band at or near $348 \mathrm{bp}$ (wild-type size) corresponding to repeat sizes of less than approximately 60 repeats (approximately $650 \mathrm{bp}$ ) identified patients as heterozygotes. As an internal control to prevent false positives, standard PCR was also performed simultaneously on the same sample with primers designed to amplify a 282-bp band from the SPG11 gene (figure e-1, links.lww.com/NXG/A266).

For a proportion of samples at the University of Chicago, 3 separate reactions each using $100 \mathrm{ng}$ of genomic DNA were performed to confirm the existence of a true biallelic (AAGGG) repeat expansion (figure e-2, links.lww.com/NXG/ A267). First, a flanking PCR was performed using primers that surrounded the RFC1 region of interest. The flanking primers 
Table 1 Patient demographics

\begin{tabular}{|c|c|c|c|c|}
\hline & UCLA & University of Chicago & Harvard & Combined \\
\hline \multicolumn{5}{|l|}{ A. Age and sex } \\
\hline Total & 596 & 302 & 13 & 911 \\
\hline Female $^{a}$ & $300(50.3 \%)$ & $148(49.0 \%)$ & $8(61.5 \%)$ & $456(50.1 \%$ \\
\hline Average age at onset ${ }^{b}(y)$ & $55( \pm 17)$ & $48( \pm 22)$ & $56( \pm 11)$ & $53( \pm 19)$ \\
\hline \multicolumn{5}{|l|}{ B. Clinical presentation } \\
\hline CANVAS & $3(0.5 \%)$ & $7(2.3 \%)$ & $1(7.7 \%)$ & $11(1.2 \%)$ \\
\hline Cerebellar ataxia neuropathy ${ }^{b}$ & $41(6.9 \%)$ & $18(6.0 \%)$ & $4(30.8 \%)$ & $63(6.9 \%)$ \\
\hline Episodic ataxia & $19(3.2 \%)$ & $22(7.3 \%)$ & 0 & $41(4.5 \%)$ \\
\hline MSA & $104(17.4 \%)$ & $6(2.0 \%)$ & $1(7.7 \%)$ & $111(12.2 \%$ \\
\hline Pure cerebellar ataxia & $129(21.6 \%)$ & $62(20.5 \%)$ & $2(15.4 \%)$ & $193(21.2 \%$ \\
\hline Spastic ataxia & $38(6.4 \%)$ & $24(7.9 \%)$ & $1(7.7 \%)$ & $63(6.9 \%)$ \\
\hline Spastic paraplegia & $35(5.9 \%)$ & $4(1.3 \%)$ & 0 & $39(4.3 \%)$ \\
\hline Spinocerebellar ataxia & $158(26.5 \%)$ & $144(47.9 \%)$ & $4(30.8 \%)$ & $306(33.6 \%$ \\
\hline Other & $69(11.6 \%)$ & $15(5.0 \%)$ & 0 & $84(9.2 \%)$ \\
\hline \multicolumn{5}{|l|}{ C. Race/ethnicityc } \\
\hline Asian & $54(9.1 \%)$ & $12(4.0 \%)$ & 0 & $66(7.2 \%)$ \\
\hline Native Hawaiian or Pacific Islander & $1(0.2 \%)$ & 0 & 0 & $1(0.1 \%)$ \\
\hline Native America or Alaska Native & $6(1.0 \%)$ & 0 & 0 & $6(0.7 \%)$ \\
\hline Black & $15(2.5 \%)$ & $10(3.3 \%)$ & 0 & $25(2.7 \%)$ \\
\hline White, Hispanic, or Latino & $58(9.7 \%)$ & $5(1.7 \%)$ & 0 & $63(6.9 \%)$ \\
\hline White, non-Hispanic & $393(65.9 \%)$ & $192(63.6 \%)$ & $12(92.3 \%)$ & $597(65.5 \%$ \\
\hline Unspecified & $76(12.8 \%)$ & 84 (27.8\%) & $1(7.7 \%)$ & 161 (17.7\% \\
\hline
\end{tabular}

Abbreviations: CANVAS = cerebellar ataxia, neuropathy, and vestibular areflexia syndrome; MSA = multiple system atrophy.

A) Age and sex of the enrolled subjects are shown.

B) The major clinical presentations of the patients enrolled in this study are shown. The presence of peripheral neuropathy was determined either clinically or electrophysiologically. Spastic ataxia and spastic paraplegia are distinguished based on which symptom was clinically estimated to be predominant. Spinocerebellar ataxia is used to indicate patients with cerebellar ataxia as the primary symptom but with notable features other than spasticity or neuropathy (e.g., dementia, epilepsy, or extrapyramidal signs). Although all patients exhibited ataxia, patients who did not clearly fit the major diagnostic categories listed were labeled as other (e.g., primary extrapyramidal conditions such as parkinsonism). MSA includes both possible and probable cases as defined by current diagnostic criteria.

C) Race and ethnicity of the enrolled subjects are shown. Patients who did not choose to disclose this information are listed as unspecified.

a Ten subjects in the UCLA cohort did not report sex.

${ }^{\mathrm{b}}$ Sixteen subjects in the University of Chicago cohort did not have a reported age at onset.

' Individuals identifying membership in more than 1 race were counted separately for each race.

included a labeled forward primer ${ }^{9}\left(5^{\prime}\right.$-/56-FAM/ACTGACAGTGTTTTTGCCTGT-3') $(10 \mu \mathrm{m})$ and a reverse primer ${ }^{9}$ $\left(5^{\prime}\right.$-GGCTGAGGCAGGAGATTCAC-3') $(10 \mu \mathrm{m})$. Second, RP-PCR was performed to detect individual nonpathogenic (AAAAG) motifs. The primers for the (AAAAG) RP-PCR included the same forward primer as the flanking reaction, an M13 anchor primer ( $5^{\prime}$-CAGGAAACAGCTATGACC-3') $(10 \mu \mathrm{m})$ and an (AAAAG) specific primer $\left(5^{\prime}\right.$-CAGGAAACAGCTATGACC_AAAAGAAAAGAAAAGAAAA-

GAAAAG-3') $(1 \mu \mathrm{m})$. Both the flanking and (AAAAG) RPPCR products were amplified using the Takara LA PCR kit in combination with a touchdown PCR. Third, to detect individual pathogenic (AAGGG) motifs, a PCR reaction was performed using the same forward primer as the flanking, the M13 anchor primer, and an (AAGGG) specific primer ${ }^{9}$ ( 5 ' CAGGAAACAGCTATGACC_AAGGGAAGGGAAGG-

GAAGGGAAGGG-3'). To obtain full amplification of the expanded (AAGGG) motif, the Qiagen HotStarTaq chemistry was used with $400 \mu \mathrm{m}$ of deoxyribonucleotide triphosphates using a standard PCR. All 3 products were loaded on an ABI3730xl DNA analyzer after denaturing with a 5\% GS500 Rox/formamide mixture and subsequently analyzed using GeneMarker v2.6.0 (SoftGenetics Inc.).

To validate the assays performed at the different centers, a proportion of samples $(>50 \%)$ determined to have 
heterozygous or biallelic AAGGG expansions were assessed at least 2 times by both expansion RP-PCR testing and standard PCR genotyping in 2 separate laboratories.

\section{$D A B 1$ gene repeat expansion analysis}

RP-PCR was performed to detect expansion of the normal (ATTTT) DAB1 repeat region and for detection of the pathogenic $(\text { ATTTC })_{n}$ insertion using published primers. ${ }^{11,12}$ Fragment length analysis was performed as described above.

\section{Data availability}

The data sets generated and/or analyzed during the current study are available from the corresponding author on reasonable request.

\section{Results}

We examined the prevalence of repeat expansions in RFC1 and $D A B 1$ in a large cohort from the tertiary referral Ataxia Center at UCLA. The demographics of this 596 subject cohort are described in table 1 . Average age was 55 years, $50 \%$ of the patients were female, and $66 \%$ were white, nonHispanic. The most common phenotypes were spinocerebellar ataxia $(26.5 \%)$, pure cerebellar ataxia $(21.6 \%)$, and multiple system atrophy (17.4\%). To assess for the presence of pathogenic (AAGGG) repeat expansions in RFC1, fluorescent repeat-primed fragment analysis was performed and identified at least 1 expansion in 50 of 596 patients $(8.4 \%$, figure 1 and figure e-1, links.lww.com/NXG/A266). Standard PCR was used to genotype subjects for the presence of a heterozygous or a pathogenic biallelic expansion. Nine subjects $(1.5 \%)$ were found with biallelic expansions. Of these patients, 3 subjects presented clinically with CANVAS (33\%, $100 \%$ of phenotype), 5 had cerebellar ataxia with neuropathy (56\%, $12 \%$ of phenotype), and 1 had spinocerebellar ataxia (11\%, $0.6 \%$ of phenotype).

To validate these findings, we tested 2 additional cohorts from centers in different regions of the United States, the University of Chicago (UC) and Brigham and Women's Hospital affiliated

Figure 1 RFC1 expansion analysis
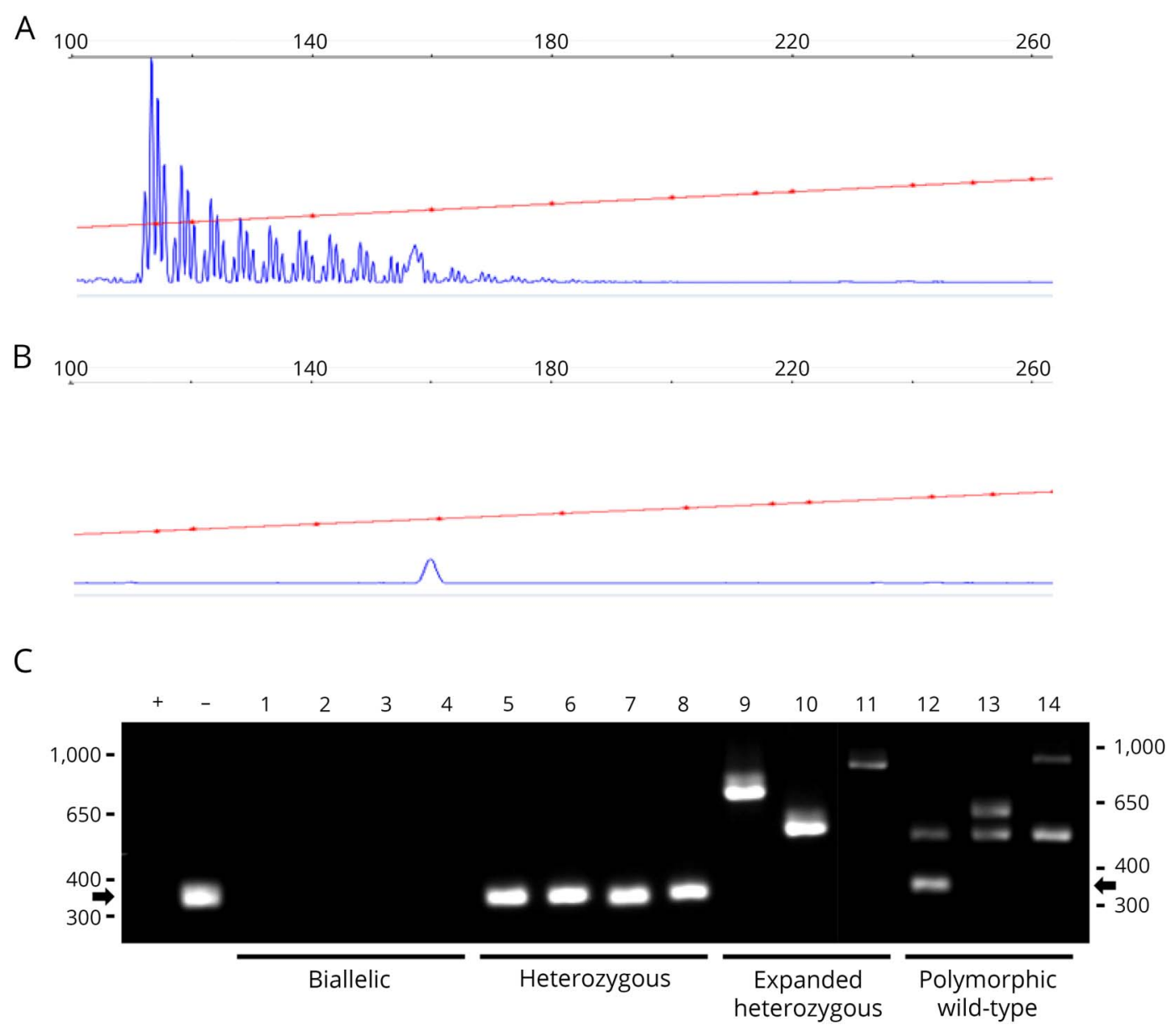

Representative RP-PCR results from a patient with disease due to (A) biallelic expanded (AAGGG) pathogenic alleles or a control individual (B) with wild-type alleles. Samples with RP-PCR evidence of an expanded RFC1 allele were genotyped by standard PCR for biallelic expansion (C). Standard PCR allows categorization of individuals as biallelic with pathogenic expansions (no band, lanes 1-4), heterozygous wild-type (348 bp band, arrow, lanes 5-8), heterozygous with a non-pathogenic polymorphic expansion (variable sized bands, lanes 9-11), or wild-type with one or more non-pathogenic polymorphic expansion(s) (variable sized band(s), lanes 12-14). + = biallelic control; - = wild-type control; $\mathrm{M}=$ marker; RFC1 = replication factor C subunit 1. 
Table 2 Demographics of patients with heterozygous expansions in the RFC1 gene

\begin{tabular}{|c|c|c|c|c|c|}
\hline Sample & Phenotype & Sex & Age at onset (y) & Ethnicity & Inheritance \\
\hline H1 & CANVAS & Female & 52 & White, non-Hispanic & Familial \\
\hline H2 & Cerebellar ataxia + neuropathy & Male & 72 & White, Hispanic, or Latino & Sporadic \\
\hline H3 & Cerebellar ataxia + neuropathy & Male & 20 & White, non-Hispanic & Familial \\
\hline H4 & Cerebellar ataxia + neuropathy & Female & 75 & White, non-Hispanic & Sporadic \\
\hline H5 & Episodic ataxia & Male & 36 & White, Hispanic, or Latino & Sporadic \\
\hline H6 & Episodic ataxia & Male & 30 & White, non-Hispanic & Familial \\
\hline H7 & Episodic ataxia & Female & 22 & White, non-Hispanic & Familial \\
\hline H8 & Episodic ataxia & Male & 10 & White, non-Hispanic & Sporadic \\
\hline H9 & MSA & Female & 66 & White, non-Hispanic & Sporadic \\
\hline H10 & MSA & Male & 63 & White, non-Hispanic & Sporadic \\
\hline H11 & MSA & Female & 56 & Asian & Sporadic \\
\hline H12 & MSA & Male & Unknown & Unspecified & Unspecified \\
\hline H13 & MSA & Male & 55 & White, non-Hispanic & Sporadic \\
\hline H14 & MSA & Female & 77 & White, non-Hispanic & Sporadic \\
\hline H15 & MSA & Male & 61 & Unspecified & Sporadic \\
\hline H16 & MSA & Male & 63 & White, non-Hispanic & Sporadic \\
\hline H17 & MSA & Male & 54 & White, non-Hispanic & Sporadic \\
\hline H18 & Pure cerebellar ataxia & Male & 72 & White, non-Hispanic & Sporadic \\
\hline H19 & Pure cerebellar ataxia & Female & 61 & White, non-Hispanic & Sporadic \\
\hline H2O & Pure cerebellar ataxia & Female & 66 & Unspecified & Sporadic \\
\hline H21 & Pure cerebellar ataxia & Female & 62 & White, non-Hispanic & Sporadic \\
\hline H22 & Pure cerebellar ataxia & Female & 76 & Unspecified & Sporadic \\
\hline H23 & Pure cerebellar ataxia & Unknown & 66 & $\begin{array}{l}\text { White, non-Hispanic, Native } \\
\text { American, or Alaska Native }\end{array}$ & Sporadic \\
\hline H24 & Pure cerebellar ataxia & Female & 37 & White, non-Hispanic & Sporadic \\
\hline H25 & Pure cerebellar ataxia & Male & 68 & White, non-Hispanic & Sporadic \\
\hline H26 & Pure cerebellar ataxia & Female & 70 & White, non-Hispanic & Sporadic \\
\hline H27 & Pure cerebellar ataxia & Male & 21 & White, Hispanic, or Latino & Sporadic \\
\hline H28 & Pure cerebellar ataxia & Male & 57 & White, non-Hispanic & Familial \\
\hline H29 & Spastic ataxia & Male & 54 & White, non-Hispanic & Sporadic \\
\hline H30 & Spastic ataxia & Female & 63 & White, Hispanic, or Latino & Sporadic \\
\hline H31 & Spastic ataxia & Male & 78 & White, non-Hispanic & Sporadic \\
\hline H32 & Spastic ataxia & Female & 57 & White, non-Hispanic & Sporadic \\
\hline H33 & Spastic ataxia & Male & 68 & White, non-Hispanic & Familial \\
\hline H34 & Spastic ataxia & Female & 38 & Unspecified & Sporadic \\
\hline H35 & Spastic ataxia & Male & 71 & Unspecified & Familial \\
\hline H36 & Spastic paraplegia & Male & 61 & White, non-Hispanic & Unspecified \\
\hline H37 & Spastic paraplegia & Female & 32 & White, non-Hispanic & Sporadic \\
\hline H38 & Spinocerebellar ataxia & Male & 84 & Unspecified & Sporadic \\
\hline
\end{tabular}


Table 2 Demographics of patients with heterozygous expansions in the RFC1 gene (continued)

\begin{tabular}{|c|c|c|c|c|c|}
\hline Sample & Phenotype & Sex & Age at onset (y) & Ethnicity & Inheritance \\
\hline H39 & Spinocerebellar ataxia & Male & 48 & White, non-Hispanic & Sporadic \\
\hline $\mathrm{H} 40$ & Spinocerebellar ataxia & Female & 66 & White, non-Hispanic & Sporadic \\
\hline H41 & Spinocerebellar ataxia & Female & 44 & White, non-Hispanic & Sporadic \\
\hline $\mathrm{H} 42$ & Spinocerebellar ataxia & Male & Unknown & Unspecified & Unspecified \\
\hline H43 & Spinocerebellar ataxia & Male & Unknown & Unspecified & Unspecified \\
\hline H44 & Spinocerebellar ataxia & Female & 69 & White, Hispanic, or Latino & Sporadic \\
\hline H45 & Spinocerebellar ataxia & Female & 76 & White, Hispanic, or Latino & Familial \\
\hline H46 & Spinocerebellar ataxia & Female & 62 & White, non-Hispanic & Familial \\
\hline H47 & Spinocerebellar ataxia & Male & 36 & White, non-Hispanic & Sporadic \\
\hline H48 & Spinocerebellar ataxia & Female & 35 & White, non-Hispanic & Familial \\
\hline H49 & Spinocerebellar ataxia & Female & & White, non-Hispanic & Familial \\
\hline H50 & Spinocerebellar ataxia & Female & 42 & White, non-Hispanic & Sporadic \\
\hline H51 & Spinocerebellar ataxia & Female & 35 & Asian & Sporadic \\
\hline H52 & Spinocerebellar ataxia & Female & 47 & Unspecified & Sporadic \\
\hline H53 & Spinocerebellar ataxia & Male & 44 & White, non-Hispanic & Sporadic \\
\hline H54 & Spinocerebellar ataxia & Male & 41 & White, non-Hispanic & Familial \\
\hline H55 & Other & Unknown & 24 & Unspecified & Unspecified \\
\hline H56 & Other & Female & 69 & White, non-Hispanic & Sporadic \\
\hline H57 & Other & Female & 35 & White, Hispanic, or Latino & Familial \\
\hline H58 & Other & Male & 78 & White, non-Hispanic & Sporadic \\
\hline H59 & Other & Unknown & 65 & Unspecified & Unspecified \\
\hline H60 & Other & Male & 53 & Unspecified & Sporadic \\
\hline H61 & Other & Female & 55 & White, non-Hispanic & Familial \\
\hline H62 & Other & Female & 24 & White, non-Hispanic & Sporadic \\
\hline
\end{tabular}

Abbreviations: CANVAS = cerebellar ataxia, neuropathy, and vestibular areflexia syndrome; MSA = multiple system atrophy; RFC1 = replication factor C subunit 1.

with Harvard Medical School. Demographics were similar to the UCLA cohort (table 1). The larger UC cohort, consisting of both sporadic and familial cases with roughly one-third of subjects originating from Canada, showed heterozygous expansions in 20 individuals (6.6\%) and pathogenic biallelic expansion in 17 patients (5.6\%) (figure e-2, links.lww.com/ NXG/A267). Four subjects had CANVAS (24\%, 57\% of phenotype), 7 had cerebellar ataxia with neuropathy ( $41 \%, 39 \%$ of phenotype), 4 had pure cerebellar ataxia $(23.5 \%, 6.5 \%$ of phenotype), and 2 had spinocerebellar ataxia (12\%, $1.4 \%$ of phenotype). In the smaller Harvard cohort, 1 individual showed heterozygous expansion (7.7\%), and 3 of 13 patients (23\%) had pathogenic biallelic expansions. Two of these had cerebellar ataxia with neuropathy $(67 \%, 50 \%$ of phenotype), while 1 had CANVAS (33\%, 100\% of phenotype). Collectively, 62 individuals were found with heterozygous expansion $(6.8 \%, 62 / 911$, table 2), and 29 of 911 subjects showed pathogenic biallelic expansions across all cohorts for a total prevalence of 3.2\% (29/ 911, table 3). Of the biallelic cases, the majority of the patients were white (24/29, 83\%), 1 patient was Hispanic (1/29, 3.4\%), and the race/ethnicity of 5 patients was not reported (17\%). Twelve of the cases showed sporadic onset (41\%). In total, 8 subjects had CANVAS (28\%, $73 \%$ of phenotype), 14 had cerebellar ataxia with neuropathy ( $48 \%, 22 \%$ of phenotype), 4 had pure cerebellar ataxia $(14 \%, 2.1 \%$ of phenotype), and 3 had spinocerebellar ataxia (10\%, $1.0 \%$ of phenotype).

For $D A B 1$ repeat expansion analysis, 83/596 (13.9\%) subjects showed an expanded ATTTT allele by RP-PCR analysis; however, none of these patients possessed the pathogenic ATTTC insertion, indicating that no patients within the cohort had SCA37. 
Table 3 Demographics of patients with biallelic expansions in the RFC1 gene

\begin{tabular}{|c|c|c|c|c|c|}
\hline Sample & Phenotype & Sex & Age at onset (y) & Ethnicity & Inheritance \\
\hline B1 & CANVAS & Male & 78 & White, non-Hispanic & Sporadic \\
\hline B2 & CANVAS & Female & 69 & White, non-Hispanic & Familial \\
\hline B3 & CANVAS & Male & 63 & White, non-Hispanic & Familial \\
\hline B4 & CANVAS & Female & 33 & White, non-Hispanic & Familial \\
\hline B5 & CANVAS & Male & 40 & White, non-Hispanic & Sporadic \\
\hline B6 & CANVAS & Female & 61 & Unspecified & Unknown \\
\hline B7 & CANVAS & Female & 56 & White, non-Hispanic & Sporadic \\
\hline B8 & CANVAS & Male & 60 & White, non-Hispanic & Sporadic \\
\hline B9 & Cerebellar ataxia + neuropathy & Female & 81 & White, non-Hispanic & Familial \\
\hline B10 & Cerebellar ataxia + neuropathy & Female & 66 & White, Hispanic, or Latino & Familial \\
\hline B11 & Cerebellar ataxia + neuropathy & Female & 71 & White, non-Hispanic & Sporadic \\
\hline B12 & Cerebellar ataxia + neuropathy & Male & 69 & White, non-Hispanic & Sporadic \\
\hline B13 & Cerebellar ataxia + neuropathy & Female & 71 & White, non-Hispanic & Sporadic \\
\hline B14 & Cerebellar ataxia + neuropathy & Female & 42 & White, non-Hispanic & Familial \\
\hline B15 & Cerebellar ataxia + neuropathy & Female & 39 & White, non-Hispanic & Familial \\
\hline B16 & Cerebellar ataxia + neuropathy & Male & 38 & White, non-Hispanic & Familial \\
\hline B17 & Cerebellar ataxia + neuropathy & Female & 64 & Unspecified & Familial \\
\hline B18 & Cerebellar ataxia + neuropathy & Female & 55 & Unspecified & Familial \\
\hline B19 & Cerebellar ataxia + neuropathy & Female & 45 & White, non-Hispanic & Sporadic \\
\hline B20 & Cerebellar ataxia + neuropathy & Male & 37 & White, non-Hispanic & Familial \\
\hline B21 & Cerebellar ataxia + neuropathy & Female & 55 & White, non-Hispanic & Sporadic \\
\hline B22 & Cerebellar ataxia + neuropathy & Female & 64 & White, non-Hispanic & Sporadic \\
\hline B23 & Pure cerebellar ataxia & Male & 45 & Unspecified & Familial \\
\hline B24 & Pure cerebellar ataxia & Female & 76 & White, non-Hispanic & Familial \\
\hline B25 & Pure cerebellar ataxia & Female & 62 & White, non-Hispanic & Familial \\
\hline B26 & Pure cerebellar ataxia & Male & 55 & White, non-Hispanic & Familial \\
\hline B27 & Spinocerebellar ataxia & Female & Unknown & Unspecified & Unknown \\
\hline B28 & Spinocerebellar ataxia & Male & 45 & White, non-Hispanic & Sporadic \\
\hline B29 & Spinocerebellar ataxia & Female & 38 & White, non-Hispanic & Sporadic \\
\hline
\end{tabular}

Abbreviations: CANVAS = cerebellar ataxia, neuropathy, and vestibular areflexia syndrome; $R F C 1=$ replication factor $\mathrm{C}$ subunit 1 .

\section{Discussion}

Overall, in a large undiagnosed ataxia cohort of 911 patients from 3 tertiary referral centers in the United States, biallelic pathogenic (AAGGG) repeat expansions in RFC1 were observed in $3.2 \%(\mathrm{n}=29,95 \%$ CI $2.0 \%-4.3 \%)$ of patients from the United States $(25 / 29,86 \%)$ and Canada (4/29, $14 \%)$. The observation that the majority of cases $(24 / 24$, $100 \%$, table 3 ), where ethnicity was known, were white of
European ancestry is consistent with previous reports. ${ }^{9,10} \mathrm{Of}$ the heterozygotes with race and ethnicity data available, $96 \%$ (47/49, table 2) were of white ancestry, and overall, single or biallelic expansions were detected in $7.1 \%$ and $3.6 \%$, respectively, of the total white population surveyed in this study. The high rate of heterozygosity $(6.8 \%)$ in our cohort is notable but is similar to 1 previous study, which calculated an allele frequency of $4 \%$ in control populations of 69 and 133 individuals based on haplotype in next-generation 
sequencing data sets, ${ }^{10}$ although another study found a frequency of $0.7 \%$ in a cohort of 304 healthy controls using RPPCR. ${ }^{9}$ Although our methods cannot accurately size larger repeats, standard PCR analysis indicated that under the conditions of our AAGGG RP-PCR assay, we were able to detect small expansions up to 60 repeats above wild type ( $\sim 650 \mathrm{bp}$, figure 1 and figure e-1, links.lww.com/NXG/ A266), and therefore, we suspect that our high rate of detection may be due, in part, to the detection of confounding mildly expanded alleles below the estimated 400 repeat margin of pathogenicity ${ }^{9}$ (figure 1 and figure e-1, links.lww. $\mathrm{com} / \mathrm{NXG} / \mathrm{A} 266)$. It is interesting to note that small AAGGG expansions have not previously been reported in patients or controls, ${ }^{9,10}$ and because all subjects tested presented with some form of cerebellar ataxia, we cannot exclude the possibility that expanded AAGGG repeats may contribute to the development of cerebellar ataxia in some heterozygous individuals. We also cannot rule out a contribution of false-positive detection of other small polymorphic nonpathogenic non-AAGGG repeats ${ }^{9}$ in some heterozygous individuals. We did confirm all biallelic subjects with RPPCR and standard PCR in at least 2 experiments each across 2 separate laboratories and further determined that none of these individuals harbored the most common nonpathogenic expanded repeat, $\mathrm{AAAAG}^{9}$ (data not shown).

In addition, the pathogenic (ATTTC) repeat in the DAB1 gene, causative for SCA37, was not observed in our large undiagnosed ataxia cohort of 596 individuals of mostly white, non-Hispanic ancestry, consistent with the observation of a founder effect in the Iberian Peninsula ${ }^{11,13}$ and suggesting that although this disorder should be considered in that population, it is likely extremely rare in the United States. Although no pathogenic ATTTC insertions were found, it is possible that extremely large repeats of ATTTT flanking a pathogenic ATTTC insertion might prevent amplification of products from the RP-PCR, so false negatives cannot be ruled out in this study, although this has not been commonly observed in published reports. ${ }^{11,12}$

Consistent with previous reports, our study identified biallelic RFC1 expansions in a high percentage of patients with CANVAS $(\mathrm{n}=8,73 \%)$ and cerebellar ataxia with neuropathy $^{9}(\mathrm{n}=14,22 \%)$. Although we do not have electrophysiologic data on all subjects, of the biallelic patients identified, all appeared to have a large fiber neuropathy (data not shown), which would be an important focus for further clinical investigation. In addition, we also observed biallelic expansion in a notable percentage of patients with pure cerebellar ataxia $(n=4,2.1 \%)$ and generalized spinocerebellar ataxia $(\mathrm{n}=3,1.0 \%)$, a frequency on par with the majority of rare ataxic disorders identifiable by clinical sequencing. ${ }^{2}$ Based on this study, the presence of neuropathy confers a $20.1 \%$ absolute benefit to testing (95\% CI 9.7\%-30.6\%) over pure cerebellar ataxia alone, and the presence of both neuropathy and vestibulopathy further increases this to $70.6 \%$ (95\% CI 44.2\%-97.0\%), with biallelic
RFC1 expansions anticipated in 1 of every 5.0 (95\% CI $3.3-10.3)$ and 1 of every 1.4 (95\% CI 1.0-2.3) patients tested, respectively. Taken together, these results suggest that RFC1 expansion testing is high yield in cases of CANVAS and cerebellar ataxia with neuropathy but should also be considered in the genetic workup of patients with undiagnosed pure cerebellar and spinocerebellar ataxia.

\section{Acknowledgment}

The authors thank all the patients and their families for their participation in this study.

\section{Study funding}

This work was supported by the National Institute for Neurological Disorders and Stroke [R01NS082094 to BLF]. BLF acknowledges support through donations to the University of California by the Rochester Ataxia Foundation. PJL was supported by the Vincent Chiodo Foundation. CMG and VK acknowledge support from the National Ataxia Foundation and the Brigham Research Institute.

\section{Disclosure}

All authors declare that there is no conflict of interest. Go to Neurology.org/NG for full disclosures.

\section{Publication history}

This manuscript was previously posted on bioRxiv: doi: 10.1101/790006. Received by Neurology: Genetics November 7, 2019. Accepted in final form March 15, 2020.

\begin{tabular}{|c|c|c|}
\hline Name & Location & Contribution \\
\hline $\begin{array}{l}\text { Dona Aboud } \\
\text { Syriani }\end{array}$ & $\begin{array}{l}\text { University of California, } \\
\text { Los Angeles }\end{array}$ & $\begin{array}{l}\text { Acquisition of data, } \\
\text { analysis of data, and } \\
\text { drafting of the manuscript }\end{array}$ \\
\hline $\begin{array}{l}\text { Darice Wong, } \\
\text { PhD }\end{array}$ & $\begin{array}{l}\text { University of California, } \\
\text { Los Angeles }\end{array}$ & $\begin{array}{l}\text { Analysis of data, study } \\
\text { design, and drafting of the } \\
\text { manuscript }\end{array}$ \\
\hline $\begin{array}{l}\text { Claudio M. De } \\
\text { Gusmao, MD }\end{array}$ & $\begin{array}{l}\text { Brigham and Women' } \\
\text { Hospital and Harvard } \\
\text { Medical School }\end{array}$ & $\begin{array}{l}\text { Acquisition of data and } \\
\text { revision of the manuscript } \\
\text { for intellectual content }\end{array}$ \\
\hline $\begin{array}{l}\text { Sameer } \\
\text { Andani, BS }\end{array}$ & University of Chicago & $\begin{array}{l}\text { Acquisition of data, } \\
\text { analysis of data, and } \\
\text { revision of the manuscript } \\
\text { for intellectual } \\
\text { content }\end{array}$ \\
\hline $\begin{array}{l}\text { Yuanming } \\
\text { Mao, BS }\end{array}$ & $\begin{array}{l}\text { University of California, } \\
\text { Los Angeles }\end{array}$ & $\begin{array}{l}\text { Acquisition of data, } \\
\text { analysis of data, and } \\
\text { drafting of the manuscript } \\
\text { for intellectual content }\end{array}$ \\
\hline $\begin{array}{l}\text { May } \\
\text { Sanyoura, } \\
\text { PhD }\end{array}$ & University of Chicago & $\begin{array}{l}\text { Acquisition of data, } \\
\text { analysis of data, and } \\
\text { revision of the manuscript } \\
\text { for intellectual } \\
\text { content }\end{array}$ \\
\hline $\begin{array}{l}\text { Giacomo } \\
\text { Glotzer }\end{array}$ & University of Chicago & $\begin{array}{l}\text { Acquisition of data and } \\
\text { revision of the manuscript } \\
\text { for intellectual } \\
\text { content }\end{array}$ \\
\hline
\end{tabular}


Appendix (continued)

\begin{tabular}{|c|c|c|}
\hline Name & Location & Contribution \\
\hline $\begin{array}{l}\text { Paul J. } \\
\text { Lockhart, } \\
\text { PhD }\end{array}$ & $\begin{array}{l}\text { Murdoch Children' } \\
\text { Research Institute }\end{array}$ & $\begin{array}{l}\text { Study design and revision } \\
\text { of the manuscript for } \\
\text { intellectual } \\
\text { content }\end{array}$ \\
\hline $\begin{array}{l}\text { Sharon } \\
\text { Hassin-Baer, } \\
\text { MD }\end{array}$ & $\begin{array}{l}\text { Sackler Faculty of } \\
\text { Medicine, Tel-Aviv } \\
\text { University, Tel-Aviv, Israel }\end{array}$ & $\begin{array}{l}\text { Acquisition of } \\
\text { data and revision } \\
\text { of the manuscript } \\
\text { for intellectual } \\
\text { content }\end{array}$ \\
\hline $\begin{array}{l}\text { Vikram } \\
\text { Khurana, MD, } \\
\text { PhD }\end{array}$ & $\begin{array}{l}\text { Brigham and Women's } \\
\text { Hospital and Harvard } \\
\text { Medical School }\end{array}$ & $\begin{array}{l}\text { Acquisition of } \\
\text { data, study } \\
\text { design, and } \\
\text { revision of the manuscript } \\
\text { for intellectual } \\
\text { content }\end{array}$ \\
\hline $\begin{array}{l}\text { Christopher } \\
\text { M. Gomez, } \\
\text { MD, PhD }\end{array}$ & $\begin{array}{l}\text { University of Chicago, } \\
\text { Chicago }\end{array}$ & $\begin{array}{l}\text { Acquisition of } \\
\text { data, study design, } \\
\text { analysis of data, } \\
\text { and revision } \\
\text { of the manuscript } \\
\text { for intellectual } \\
\text { content }\end{array}$ \\
\hline $\begin{array}{l}\text { Susan } \\
\text { Perlman, MD }\end{array}$ & $\begin{array}{l}\text { University of California, } \\
\text { Los Angeles }\end{array}$ & $\begin{array}{l}\text { Acquisition of } \\
\text { data and } \\
\text { revision of the manuscript } \\
\text { for intellectual } \\
\text { content }\end{array}$ \\
\hline $\begin{array}{l}\text { Soma Das, } \\
\text { PhD }\end{array}$ & University of Chicago & $\begin{array}{l}\text { Acquisition of } \\
\text { data, data } \\
\text { analysis, study } \\
\text { design, and } \\
\text { revision of the manuscript } \\
\text { for intellectual } \\
\text { content }\end{array}$ \\
\hline
\end{tabular}

Appendix (continued)

\begin{tabular}{|c|c|c|}
\hline Name & Location & Contribution \\
\hline $\begin{array}{l}\text { Brent L. } \\
\text { Fogel, MD, } \\
\text { PhD }\end{array}$ & $\begin{array}{l}\text { University of California, } \\
\text { Los Angeles }\end{array}$ & $\begin{array}{l}\text { Study design and } \\
\text { supervision, acquisition of } \\
\text { data, analysis of data, and } \\
\text { drafting and revision of } \\
\text { the manuscript for } \\
\text { intellectual content }\end{array}$ \\
\hline
\end{tabular}

\section{References}

1. Sun M, Johnson AK, Nelakuditi V, et al. Targeted exome analysis identifies the genetic basis of disease in over $50 \%$ of patients with a wide range of ataxia-related phenotypes. Genet Med 2019;21:195-206.

2. Fogel BL, Lee H, Deignan JL, et al. Exome sequencing in the clinical diagnosis of sporadic or familial cerebellar ataxia. JAMA Neurol 2014;71:1237-1246.

3. Rexach J, Lee H, Martinez-Agosto JA, Nemeth AH, Fogel BL. Clinical application of nextgeneration sequencing to the practice of neurology. Lancet Neurol 2019;18:492-503.

4. Ngo KJ, Rexach JE, Lee $\mathrm{H}$, et al. A diagnostic ceiling for exome sequencing in cerebellar ataxia and related neurological disorders. Hum Mutat 2020;41:487-501.

5. Paulson H. Repeat expansion diseases. Handb Clin Neurol 2018;147:105-123.

6. Mundwiler A, Shakkottai VG. Autosomal-dominant cerebellar ataxias. Handb Clin Neurol 2018;147:173-185.

7. Fogel BL. Autosomal-recessive cerebellar ataxias. Handb Clin Neurol 2018;147: 187-209.

8. Wallace SE, Bird TD. Molecular genetic testing for hereditary ataxia: what every neurologist should know. Neurol Clin Pract 2018;8:27-32.

9. Cortese A, Simone R, Sullivan R, et al. Biallelic expansion of an intronic repeat in RFC1 is a common cause of late-onset ataxia. Nat Genet 2019;51:649-658.

10. Rafehi H, Szmulewicz DJ, Bennett MF, et al. Bioinformatics-based identification of expanded repeats: a non-reference intronic pentamer expansion in RFC1 causes CANVAS. Am J Hum Genet 2019;105:151-165.

11. Seixas AI, Loureiro JR, Costa C, et al. A pentanucleotide ATTTC repeat insertion in the non-coding region of DAB1, mapping to SCA37, causes spinocerebellar ataxia. Am J Hum Genet 2017;101:87-103.

12. Loureiro JR, Oliveira CL, Sequeiros J, Silveira I. A repeat-primed PCR assay for pentanucleotide repeat alleles in spinocerebellar ataxia type 37. J Hum Genet 2018;63:981-987.

13. Corral-Juan M, Serrano-Munuera C, Rabano A, et al. Clinical, genetic and neuropathological characterization of spinocerebellar ataxia type 37. Brain 2018;141: 1981-1997. 


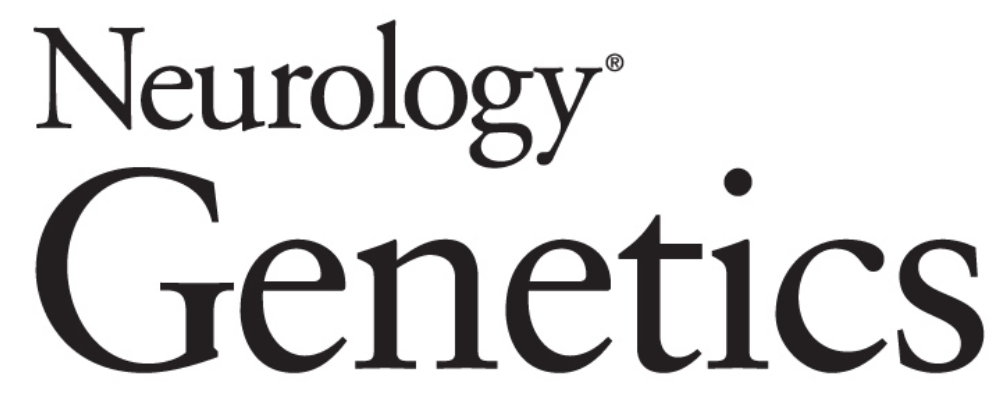

Prevalence of $\boldsymbol{R F C 1 - m e d i a t e d ~ s p i n o c e r e b e l l a r ~ a t a x i a ~ i n ~ a ~ N o r t h ~ A m e r i c a n ~ a t a x i a ~}$ Dona Aboud Syriani, Darice Wong, Sameer Andani, et al. Neurol Genet 2020;6;

DOI 10.1212/NXG.0000000000000440

This information is current as of May 20, 2020

Neurol Genet is an official journal of the American Academy of Neurology. Published since April 2015, it is an open-access, online-only, continuous publication journal. Copyright Copyright $(2020$ The Author(s). Published by Wolters Kluwer Health, Inc. on behalf of the American Academy of Neurology.. All rights reserved. Online ISSN: 2376-7839.

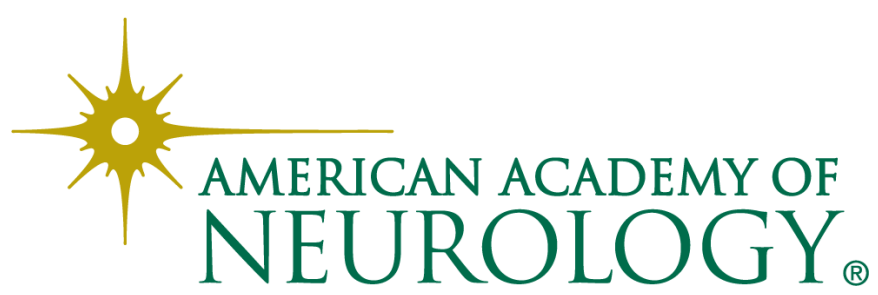




\section{Updated Information \& Services}

References

Citations

Subspecialty Collections

Permissions \& Licensing

Reprints including high resolution figures, can be found at: http://ng.neurology.org/content/6/3/e440.full.html

This article cites 13 articles, 1 of which you can access for free at: http://ng.neurology.org/content/6/3/e440.full.html\#\#ref-list-1

This article has been cited by 9 HighWire-hosted articles: http://ng.neurology.org/content/6/3/e440.full.html\#\#otherarticles

This article, along with others on similar topics, appears in the following collection(s):

\section{Cerebellum}

http://ng.neurology.org//cgi/collection/cerebellum

Gait disorders/ataxia

http://ng.neurology.org//cgi/collection/gait_disorders_ataxia

Spinocerebellar ataxia

http://ng.neurology.org//cgi/collection/spinocerebellar_ataxia

Trinucleotide repeat diseases

http://ng.neurology.org//cgi/collection/trinucleotide_repeat_diseases

Vertigo

http://ng.neurology.org//cgi/collection/vertigo

Information about reproducing this article in parts (figures,tables) or in its entirety can be found online at:

http://ng.neurology.org/misc/about.xhtml\#permissions

Information about ordering reprints can be found online:

http://ng.neurology.org/misc/addir.xhtml\#reprintsus

Neurol Genet is an official journal of the American Academy of Neurology. Published since April 2015, it is an open-access, online-only, continuous publication journal. Copyright Copyright ( 2020 The Author(s). Published by Wolters Kluwer Health, Inc. on behalf of the American Academy of Neurology.. All rights reserved. Online ISSN: 2376-7839.

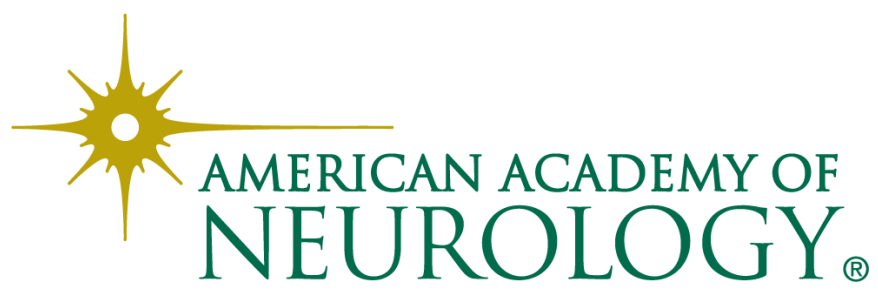

